\title{
Centralized Grid electricity and distributed electricity: A case study of Nigeria
}

\author{
Olumide Adewole Towoju ${ }^{1,}{ }^{*}$ and Oluwatoyin A Oladele ${ }^{2}$ \\ ${ }^{1}$ Department of Mechanical engineering, Lead City University, Nigeria. \\ 2 Operations Department, Pacific Energy Company Limited, Olorunshogo, Nigeria.
}

Global Journal of Engineering and Technology Advances, 2021, 08(03), 057-061

Publication history: Received on 18 August 2021; revised on 19 September 2021; accepted on 21 September 2021

Article DOI: https://doi.org/10.30574/gjeta.2021.8.3.0118

\begin{abstract}
The push for the liberalization of the electricity market and the concern over climate change is an impetus for the call to a paradigm shift in electricity generation mode. Electricity generation can either be centralized or distributed. The major selling points for distributed electricity generation are energy security and greenhouse gas reduction. However, some other factors weigh an impact on electricity generation. Nigeria is a country battling to meet the electricity demand of its populace. Some of the identified factors are localized to Nigeria to come up with a suitable generation model. This study considers factors such as energy security and reliability, environmental impact, energy efficiency, cost, and rural electrification. These factors led to a basis to propose a suitable generation model for the country based on her peculiarities. Distributed electricity generation promises an edge over centralized electricity generation while considering energy security, efficiency, rural electrification, and capital investment cost. Distributed generation allows access to the deployment of clean energy. However, this is not to construe that its adoption will automatically guaranty reduced emissions.
\end{abstract}

Keywords: Environment; Fossil fuels; Generation; Renewables; Transmission

\section{Introduction}

Nigeria's electricity generation target for the year 2020 stands at about 40 GW [1]. However, the current installed capacity stands at about $11 \mathrm{GW}$, and the average generation capacity results in an average per capita consumption of about $150 \mathrm{kWh}$ [2]. A shortfall of about $29 \mathrm{GW}$ is the difference between the country's electricity target and reality. The shortfall can be bridged either with grid or distributed electricity. The issued license for power generation plants in the country stands to the tune of $26 \mathrm{GW}$; the installed capacity stands at $11 \mathrm{GW}$ while available generated electricity falls below $5 \mathrm{GW}$ [1]. The difference in the installed capacity and the available capacity is partly due to gas supply shortages and mainly due to the transmission and distribution challenges [2]. Electricity generation and supply to the final consumers are possible using grid generation or the distributed generation [2]. The grid generation has been for over a century and still enjoys high utilization by the advanced nations [3]. It entails the interconnection of generated electricity from different locations through the grid.

Distributed electricity generation entails the power consumption at the point of or near the generation site $[4,5]$ and allows for greater use of alternative energies. It is usually a small-scale generation unit. With a large deficit of power required to meet the country's electricity needs and the target, the nation needs to adopt a generation and supply mode that is cost-efficient.

\footnotetext{
${ }^{*}$ Corresponding author: Olumide Adewole Towoju

Department of Mechanical engineering, Lead City University, Nigeria. 
This study seeks to localize some factors that influence the electricity generation and supply mode to Nigeria. And propose the better of the grid electricity and the distributed electricity to adopt for offsetting the country's electricity deficit.

\section{Security and reliability}

The insusceptibility of energy supplies to interruptions is one of the conditions for energy security. There must be access to adequate, affordable, and regular supplies of (clean) energy. Distributed electricity generation has high flexibilities making them more robust and reliable [6]; due to its adaptability to the available energy source and the capability to reduce network loading at critical periods $[7,8]$. It can form part of a micro grid connected to large delivery systems or just to a single structure [5]. Its adaptability to using the available energy source brings about fuel diversity. Thus distributed generation allows for energy security as against that for a centralized generation [9].

Large conventional generation plants rely on fossil fuels, nuclear fuels, and large dams. The generated energy from such plants connects to the grid. The location of the plants is dependent on the availability of energy sources. And in many instances might be subjected to some external forces. The high fluctuation in the cost of fossil fuels also contributes to making the dependence on it for electricity generation unsecure $[10,11]$. The reliability achieved by linking different generation sources to the grid that can compensate for a loss in one or more is still a plus for the grid generation [10]. The presence of gas in the southern part of Nigeria has made it home to many of the conventional generation plants. The cities up north of the country are hence, susceptible to electricity disruptions if anything happens down south. The core northern part of the country is thus unsecured based on grid generation. However, many of these areas can have electricity using their available peculiar resources; solar and wind energy with the adoption of distributed generation. In the western part of the country, asides solar, micro and mini-hydro dams can be incorporated into the distributed generation networks thereby securing the electricity supply to the areas.

Many advanced nations in Europe are gradually moving towards renewables for the generation of their electricity. The motive behind this is the benefit of a low rate of $\mathrm{CO}_{2}$ emission per $\mathrm{kWh}$ [12] and also energy security. The continuous depletion of fossil fuel reserves is a cause of concern about the security of energy availability in the nearest future if the dependence on it continues unabated. Nigeria must not be allowed to trail behind, grid electricity relies heavily on fossils fuels, and large hydro dams in this part of the world as Nuclear power plants are still but a mirage. The reliance on fossil fuels is an indication of unsecured energy. The earlier the country adopts the local renewables in the generation of her electricity in the distributed mode, the better it will be for the country in terms of flexibility [13], energy security [14], and reliability. Despite being richly blessed with gas reserves; Nigeria still suffers from gas unavailability for electricity generation.

\section{Environmental Impact}

The impact of electricity generation needs to be taken seriously because of its attendant effect on the environment. Distributed generation can be associated with either conventional or renewable energy technology [15]. The adoption of conventional energy technology in a distributed generation will affect the environment [16] just like the grid generation fueled with fossil fuels but at a smaller scale. However, adopting renewable energy technology will result in a reduction of greenhouse gases emission [5, 9, 16-17] hence, it is environmentally friendlier.

Grid generation is favored by large electricity generation from different locations. To be environmentally friendly, hydro and wind generation will always come to mind due to the reliable and stable advantage of the former [18] and the costeffective nature of the latter; onshore wind [19]. However, the relatively high cost required for hydro-dam construction coupled with the disruptions it could cause to the ecosystem [18] is an issue that requires pondering on. Nigeria is not currently buoyant economically, no thanks to many factors despite being a natural resources blessed nation. The attendant high cost needed for dam construction indicates that the construction of such dams will linger on for many years and might even become an abandoned project. Electricity generation from wind is cost-effective, but the investment cost is high due to the high state of technology needed for its optimal performance [20]. The challenge of ending up being an abandoned project surely thus awaits it.

To be able to bridge the shortfall while doing little or no harm to the environment by utilizing the scarce resources, renewables thus come to mind. It is, however, important to note that renewables like biomass and biofuels also do harm the environment [9,21-22], and consider this in arriving at a better decision. The generated electricity from renewables is better suited to the distributed mode, one of its major drawbacks has been its integration into the grid [9, 23]. Environmental constraints are a major pushing block against the continuous use of the centralized generation. Pushing 
the plants to remote areas does not reduce the net effect on the environment but can even add due to losses of electricity which is certainly generated from fuel. Electricity generation in Nigeria is mainly dependent on gas which is cleaner than other fossil fuels, however, the attendant effect of gas exploration on the environment should be an incentive to looking towards localized renewables for distributed generation. Having to transport electricity over a long distance from the central stations increases the susceptibilities to transmission and distribution losses [10] which implies emission for unused energy.

\section{Energy Efficiency}

The efficiency of fossil fuel operated power plants is on the low side and is more for low-cost fuels like coal [24]. Unutilized heat of combustion results in a loss of a large amount of energy. The improvement of efficiency requires utilizing this inherent energy in the waste flue gases rather than discarding it. A general means of this utilization is to use the plant in a cogenerating mode. Centralized grid generation does not favour cogeneration as heat and steam shipment pose a problem [10]. Adopting distributed generation can thus bring about improved efficiency of plants as it allows for cogeneration. Also, line losses are characteristic of grid generation and negatively impacts energy efficiency $[2,10]$. Distributed generation is not immune to line losses, but with shipment over a shorter distance, $[2,7,10]$ the losses are minimal.

The high-level losses experienced on the nation's electricity transmission grid network [2, 25] takes a high toll on efficiency. However, distributed electricity does not require the transmission grid [2, 10], a plus for efficiency. Many industries and homes in the country also carry out heating using electricity or combustion of fossil fuels. Adopting distributed generation in cogeneration mode will thus result in increased energy efficiencies and reduced cost.

Distributed generation allows the use of technology varieties [10] and puts the end-user at the liberty of adopting the most efficient of the different technologies. The sole adoption of solar energy can however, pose a challenge during unfavourable weather periods [26].

\section{Cost}

The economics of scale comes into play in centralized grid generation [10] and make the cost per unit of electricity generation lower. The capital requirement for the construction of plants for centralized grid generation is, however, immerse. This is irrespective of the conventional ones or from renewables $[9,22]$. Nigeria's economy is in a bad state, and the high initial cost of plant construction is a stumbling block. The capital investment required for the construction of distributed electricity plants is lower. Using the smaller version of the plants in the centralized generation, its return on investment can be higher for cogeneration plants $[8,10]$. The cost competitiveness of the distributed electricity generation is dependent on ancillary services like heating. A consideration concerning this has to be suffix for its adoption in the country.

The cost of transmission and distribution to areas far away from the generating plants also adds to the total [2, 27]. It can account for up to $30 \%$ of it [10]. The distributed generation does not require a transmission grid $[2,10]$ and the cost of the transmission lines is hence, avoided. When the captive generation mode is adopted, the required distribution lines are minimal, leading to a further reduction in the losses.

The suitability of a variety of fuel usage in distributed electricity generation [9] can be a crucial factor in running cost as waste gases from landfills can be utilized in electricity generation $[9,10]$. The variety of technology that distributed generation also enjoys [10] also comes with the added advantage of selecting the most cost-effective one peculiar to the location and positively impact the economy [28]. The economy of the local communities will witness a boost with the adoption of distributed electricity. Also, it will create an avenue to utilize many of the vast resources.

\section{Rural Electrification}

The electrification rate in Sub-Saharan Africa is at an alarmingly low level [29] due to many reasons. The cost of shipping electricity to remote places far from the power stations is a contributory factor and a challenge to rural electrification. Reconciling the shipment costs with a low level of consumption of the remote places [10, 29] is a challenge. A key to overcoming the challenge of shipment cost and the uneconomical huddle lies with the distributed generation which encourages ownership [30-31]. Nigeria has formulated policies to bridge the gap between urban and rural electrification rates, and it is high time we adopted distributed generation. 


\section{Conclusion}

Many homes and establishments in the country are knowingly and unknowingly already involved in the distributed generation of electricity. However, this is achieved most often in ways that negatively affect the environment and at higher costs because of the reliance on oil (petrol and diesel) for individual electricity generation. Based on the considered factors;

- Distributed electricity generation will offer energy security to the country more than centralized generation can.

- Employing the use of renewables in a distributed generation will help in climate change check. However, its adoption with conventional fuels will have a corresponding impact as centralized generation on the environment but on a smaller scale.

- The efficiency of centralized plants has improved over the years. However, the losses during shipment have continued to be a cog in the wheel. The shipment losses are not a critical challenge for distributed generation coupled with the fact that the plants can be used in a cogeneration mode, hence, a better option in terms of efficiency.

- The economy of scale favours centralized generation in terms of the cost of energy per unit. However, the high amount of capital required for its construction shifts the balance towards the distributed electricity generation mode, whose capital investment costs are minimal with the option of a variety of fuel usage.

- Economics favour the adoption of distributed electricity generation in rural areas over a centralized generation model.

- However, as promising as distributed electricity generation seems, technical hurdles can crop up and must be crossed to enjoy the full benefit of its adoption.

\section{Compliance with ethical standards}

\section{Acknowledgments}

We acknowledge Lead City University, Nigeria for providing the enabling environment to carry out this study.

\section{Disclosure of conflict of interest}

There is no conflict of interest to declare in this study.

\section{References}

[1] NERC. Generation.

[2] Towoju OA, Ishola FA, Elomien E. Decentralized electricity generation can revive Nigeria dying critical sectors. IOP Conf. Series: Material Science and Engineering, 1107(2021)012105, pp. 1-8. DOI: $10.1088 / 175799 X / 1107 / 1 / 012105$

[3] Hagemann T. Five reasons to switch to decentralized electricity generation.The Governance Post. 2017.

[4] Daiva S, Saulius G, Liudmila A. Energy Distribution Planning Models Taxonomy and Methods of Distributed Generation Systems. Energy Procedia. 2017; 107: 275 - 283.

[5] EPA. Distributed generation of electricity and its environmental impacts. Energy and Environment.

[6] Carrasco JM. et al. Power Electronic Systems for the Grid Integration of Renewable Energy Sources: a Survey." IEEE 1667898, IEEE Trans. Ind. Electron. 2006; 53: 1002.

[7] Hayes B. Chapter 9 - Distribution Generation Optimization and Energy Management, Editor(s): G.B. Gharehpetian, S. Mohammad Mousavi Agah, Distributed Generation Systems, Butterworth-Heinemann. 2017; 415-451.

[8] Lin J, Magnago FH, Foruzan E, Albarracín-Sánchez R. Chapter 8 - Market Design Issues of Distributed Generation, Editor(s): G.B. Gharehpetian, S. Mohammad Mousavi Agah, Distributed Generation Systems, ButterworthHeinemann. 2017; 369-413.

[9] Towoju OA, Ishola FA. Pros and cons of electricity generation from different available energy sources. International Review of Mechanical Engineering (IREME). 2020; 14(6): 374-380.

[10] Martin J. Distributed vs. centralized electricity generation. 2009. 
[11] Rouholamini M, Mohammadian M. Grid-price-dependent Energy Management of a Building Supplied by a Multisource System Integrated with Hydrogen." International Journal of Engineering Transactions A: Basics. 2016; $29(1): 40-48$.

[12] Towoju OA. Carbon Footprint Reduction with The Adoption of the Electricity-Powered Vehicles. International Energy Journal (IEJ). 2021; 21(1A): 101-106.

[13] Farrel J. The Challenge of Reconciling a Centralized V. Decentralized Electricity System. ILSR. 2011.

[14] Ayoo C. Towards energy security for the twenty-first century. Intechopen. 2020; 1 - 26.

[15] M AlMuhaini. Chapter 10 - Impact of Distributed Generation Integration on the Reliability of Power Distribution Systems, Editor(s): G.B. Gharehpetian, S. Mohammad Mousavi Agah, Distributed Generation Systems, Butterworth-Heinemann. 2017; 453-508.

[16] Abdolalipouradl M, Mohammadkhanib F, Khalilaryaa S, Jafarmadar S. Thermodynamic Analysis of New Cogeneration Cycle Based on Gaynarje Hotspring. International Journal of Engineering Transactions C: Aspects. 2020; 33(6): 1149-1155.

[17] Mirzaei Darian MM, Ghorreshi AM, Hajatzadeh MJ. Evaluation of Photovoltaic System Performance: A Case Study in East Azerbaijan, Iran. Iranian (Iranica) Journal of Energy \& Environment. 2020; 11(1): 75-78.

[18] Jônatas da Mata FC, Mesquita AZ, Neto RO. Comparison of The Performance, Advantages and Disadvantages of Nuclear Power Generation Compared to Other Clean Sources of Electricity. 2017 International Nuclear Atlantic Conference-INAC. 2017.

[19] Motyka M, Slaughter A, Amon C. Solar and Wind move from Mainstream to preferred. Global renewable energy trends -Deloitte Insights. 2018.

[20] Breeze P. Chapter 1 - An Introduction to Wind Power. Wind Power Generation. 2016; 1-8.

[21] Freiberg A, Scharfe J, Murta VC, Seidler A. The Use of Biomass for Electricity Generation: A Scoping Review of Health Effects on Humans in Residential and Occupational Settings. Int J Environ Res Public Health. 2018; 15(2): $1-27$.

[22] Lindwall C. Bioenergy 101. NRDC [Online]. 2019.

[23] Dash R, Swain SC. Effective Power quality improvement using Dynamic Activate compensation system with Renewable grid interfaced sources." Ain Shams Engineering Journal. 2018; 9(4): 2897-2905.

[24] Towoju OA, Ishola FA. A Case for The Internal Combustion Engine Powered Vehicle. Energy Reports. 2020; 6S2: 315-321.

[25] Get. Invest. Nigeria Energy Sector.

[26] Martynyuk V, Voynarenkob M, Boikoc J, Svistunov O. Simulation of Photovoltaic System as a Tool of a State's Energy Security. International Journal of Engineering Transactions B: Applications. 2021; 34(02): 487-492.

[27] Islam MA, Hasanuzzaman M, Rahim NA, Nahar A, Hosenuzzaman M. Global Renewable Energy-Based Electricity Generation and Smart Grid System for Energy Security. The Scientific World Journal. 2014, Article ID 197136, 2014.

[28] Klagge B, Brocke T. Decentralized electricity generation from renewable sources as a chance for local economic development: a qualitative study of two pioneer regions in Germany." Energy, Sustainability and Society. 2012; 2(5): 1-9.

[29] Torero M. The impact of rural electrification: challenges and ways forward. Matieres de Reflexion, HS. 2015; 23: 49-75.

[30] Carly S. Distributed generation: an empirical analysis of primary motivators. Energy Policy. 2009; 37 : 1648 1659.

[31] Kassa AB. Current Status, Future Potential and Barriers for Renewable Energy Development in Ethiopia. Iranian (Iranica) Journal of Energy \& Environment. 2019; 10(4): 269-274. 